\title{
Mulheres codependentes em convivência com
} familiar alcoolista

\section{Codependent women living with alcoholic family members}

\author{
Edméia Campos Meira' • Samara Santos Souza ${ }^{2} \bullet T_{\text {Thainan Alves Silva }}^{3}$ \\ Laiza Carvalho Costa $^{4} \bullet$ Larissa de Oliveira Vieira $^{5} \bullet$ Geisa Araújo Galvão $^{6} \bullet$ Edite Lago da Silva Sena $^{7}$ \\ RESUMO
}

Objetivo: Compreender as repercussões da codependência nas histórias de vida das mulheres (esposas/ex-esposa/filhas) em convivência com o familiar alcoolista, considerando as dimensões do sofrimento psicossocial das esposas/ex-esposa/filhas, os aspectos decorrentes das relações desiguais de gênero além do processo de resiliência das mulheres. Método: $O$ estudo fundamentou-se na História Oral deVida, e foi realizado em um município do interior da Bahia, Brasil, no período de abril a outubro de 2019, tendo como participantes sete mulheres (esposas/ex-esposa/filhas) vinculadas a homens alcoolistas. Obtiveram-se as histórias de vida por meio de entrevistas semiestruturadas e os dados foram analisados pela Análise de Conteúdo Temática. Resultados: Descreveram-se duas categorias: uma evidenciou os sofrimentos psicossociais das mulheres resultantes das relações de codependência e a segunda apresentou questões decorrentes dasrelaçõesdesiguais de gênero. $O$ estudo apontou que o alcoolismo afetou a saúde das mulheres (esposas/ex-esposa/filhas) nas dimensões do sofrimento psicossocial (a exemplo de alguns sentimentos relatados pelas participantes, como o medo, raiva e a vergonha). Destaca-se ainda que a relação desigual de gênero entre os homens e as esposas/ex-esposa/filhas reflete a persistência de concepções patriarcais e de desigualdade nas relações, incluindo episódios de violência. Conclusões: São necessárias ações de saúde mental voltadas ao cuidado à mulher que vivencia a relação de codependência com familiares alcoolistas, com vistas a discutir a equidade de gênero, de modo a valorizar aspectos para a promoção da saúde, intervenção em situação de adoecimento além da melhoria da qualidade de vida das mulheres. Palavras-chave: Codependência Psicológica; Relações Familiares;Alcoolismo; Relações de Gênero.

\begin{abstract}
Objective:To understand the repercussions of codependency in the life stories of women (wives / ex-wife / daughters) living with alcoholic family members, considering the dimensions of the psychosocial suffering of wives / ex-wife / daughters, the aspects arising from unequal relationships beyond the women's resilience process. Method:The study was based on the Oral History of Life, and was carried out in a municipality in the interior of Bahia, Brazil, from April to October 2019, with seven women (wives / ex-wife / daughters) linked as participants alcoholic men. Life stories were obtained through semi-structured interviews and the data were analyzed by Thematic Content Analysis. Results:Two categories were described: one highlighted the psychosocial suffering of women resulting from codependent relationships and the second presented issues arising from unequal gender relations. The study pointed out that alcoholism affected the health of women (wives / ex-wife / daughters) in the dimensions of psychosocial suffering (such as some feelings reported by the participants, such as fear, anger and shame). It is also noteworthy that the unequal gender relationship between men and wives / ex-wife / daughters reflects the persistence of patriarchal conceptions and inequality in relationships, including episodes of violence. Conclusions: Mental health actions aimed at caring for women who experience a codependency relationship with alcoholic family members are necessary, in order to discuss gender equity, in order to value aspects for health promotion, intervention in situations of illness beyond improving women's quality of life.
\end{abstract}

Keywords: Psychological Codependency; Family relationships;Alcoholism; Gender relations

NOTA

I Enfermeira pela Universidade Federal da Bahia (1982). Mestrado em Enfermagem pela Universidade Federal do Estado do Rio de Janeiro (I998) e doutorado em Memória: Linguagem e Sociedade pela Universidade Estadual do Sudoeste da Bahia (2017).Atualmente é professor adjunto da Universidade Estadual do Sudoeste da Bahia e membro do comitê institucional externo da Faculdade Independente do Nordeste.

2 Graduanda em Enfermagem pela Universidade Estadual do Sudoeste da Bahia (UESB). Bolsista no Projeto de Iniciação Cientifica "O sentido da memória de familiares em relação de convivência e cuidado com o alcoolismo". Membro do grupo de pesquisa "Grupo de Estudo e Pesquisa em Saúde Mental: Loucos por Cidadania”.

3 Enfermeira pela Universidade Estadual do Sudoeste da Bahia (2017). Mestranda em Enfermagem e Saúde Pública pelo Programa de Pós-Graduação em Enfermagem e Saúde (PPGES) da Universidade Estadual do Sudoeste da Bahia (UESB). Pós-graduação em Enfermagem do Trabalho pelo Instituto Superior de Educação Ateneu (ISEAT), Brasil (20I8); Integrante do Grupo de Estudos e Pesquisas em Saúde Mental: Loucos por Cidadania (CNPQ/UESB) desde 2015.

4 Graduanda em Enfermagem pela Universidade Estadual do Sudoeste da Bahia (UESB). Técnica em Química pelo Centro Federal de Educação Tecnológica de Minas Gerais (20I I). Atualmente atua no projeto de pesquisa intitulado como "o sentido da memória de familiares em relação de convivência e cuidado com o alcoolismo crônico".

5 Psicóloga pela Universidade Federal do Recôncavo da Bahia (UFRB). Mestrado em Ciências da Saúde, área de concentração em Saúde Pública, pelo Programa de Pós-Graduação em Enfermagem e Saúde (PPGES) da Universidade Estadual do Sudoeste da Bahia (UESB). Especialização em Gestão em Saúde pela Universidade Federal do Recôncavo da Bahia, UFRB, Especialista em Gestalt-Terapia pelo Instituto de Gestalt-Terapia da Bahia (IGTBa).

6 Enfermeira pela Universidade Estadual do Sudoeste da Bahia, Campus Jequié.Atuou em 2015 como bolsista voluntário no Projeto de extensão contínuo: Profilaxia de doenças parasitárias, em 2016 e 2017 participou do Projeto de extensão: Saúde do Coto Umbilical como bolsista voluntária.Atualmente atua no projeto de pesquisa intitulado como "o sentido da memória de familiares em relação de convivência e cuidado com o alcoolismo crônico".

7 Enfermeira pela Universidade Estadual do Sudoeste da Bahia (1989). Mestrado em Enfermagem com Área de Concentração em Saúde Pública pela Universidade Federal do Estado do Rio de Janeiro - UNIRIO (1997). Doutorado em Enfermagem - área de Concentração em Filosofia, Saúde e Sociedade pelo Programa de Pós-Graduação em Enfermagem (PEN) da Universidade Federal de Santa Catarina - UFSC (2006). 


\section{INTRODUÇÃO}

O consumo de bebidas alcoólicas faz parte da vida de muitas pessoas desde os primórdios da humanidade, uma vez que o álcool é considerado uma droga lícita, de fácil acesso e aceita pela sociedade. Entretanto, o uso de maneira exacerbada e contínua pode gerar uma condição de dependência e se caracterizar como alcoolismo, que é uma doença capaz de provocar, além de mudanças comportamentais e intelectuais no indivíduo, alterações de personalidade e humor, dificuldades no relacionamento social e familiar. Neste sentido, constitui grave problema de saúde pública ${ }^{(1-2)}$.

A convivência familiar com o alcoolista resulta em prejuízos biopsicossociais aos membros da família, especialmente às mulheres, a curto e longo prazo, ocasionando consequências, como a codependência. Nesse contexto, a codependência é considerada um transtorno emocional que acontece em indivíduos que mantém uma convivência diária com usuários de substâncias psicoativas, como aqueles que consomem o álcool ${ }^{(1-3)}$.

A mulher que convive com um familiar alcoolista pode se tornar codependente dele, seja o pai ou o cônjuge. Esta relação poderá mobilizar a mulher a desenvolver sentimento de culpa, tristeza, depressão, baixa autoestima e, principalmente, o controle e cuidado obsessivo sobre o familiar doente, colocando sua própria vida em função do outro, o que contribui para o adoecimento ${ }^{(4)}$. Esta situação tem repercussão nas desigualdades de papeis sociais no processo de cuidado, influenciado pela construção social de identidade de gênero em relações familiares ${ }^{(5-7)}$.

Destaca-se neste contexto que as concepções patriarcais e as práticas androcêntricas ainda persistem na sociedade, o que contribuem para reforçar a desigualdade de gênero, a manutenção da figura do homem em posição privilegiada sobre a mulher, além do papel de inferioridade que as mulheres exercem nos relacionamentos, incluindo a sobrecarga e risco de adoecer ao cuidar do esposo ou pai alcoolista ${ }^{(5)}$.

Enfatiza-se ainda que o fator gênero é facilitador dos aspectos de desigualdades, maus tratos e isolamento social. Assim sendo, a convivência de mulheres com um familiar alcoolista pode intensificar tais situações, implicando na fragilização emocional delas a ponto de estarem em codependência e impossibilitadas de agir em prol do próprio bem estar, além de contribuir para a manutençãoda realidade estabelecida ${ }^{(8)}$.

Desta maneira, conhecer a história oral de vida de mulheres em situação de codependência no contexto das relações com familiares alcoolistas é de suma importância para aprimorar o cuidado em saúde na perspectiva da integralidade. Assim, é necessário contemplar a assistência em saúde ao alcoolista e tambémaos membros da família, principalmente as companheirase filhasqueviven- ciam as desigualdades nas relações de papeis sociais e de gênero e se encontram em condição de vulnerabilidade no ambiente familiar.

Diante do exposto, identifica-se a importância de estudos que compreendam as relações entre o consumo abusivo de álcool pelo familiar e os diversos modos de adoecimento das mulheres/cuidadoras, de modo a contribuir para a elaboração de estratégias de cuidadopara os membros da família.

Constituiu-se a seguinte questão norteadora do estudo: Como as mulheres (esposas/ex-esposa/filhas) em convivência com familiar alcoolista significam suas histórias de vida, considerando as repercussões da codependência na condição de saúde? Para responder a essa pergunta o estudo teve como objetivo: compreender as repercussões da codependência nas histórias de vida das mulheres (esposas/ex-esposa/filhas) em convivência com o familiar alcoolista, considerando as dimensões do sofrimento psicossocial das esposas/ex-esposa/filhas, os aspectos decorrentes das relações desiguais de gênero além processo de resiliência das mulheres.

\section{MÉTODO}

Trata-se de um estudo de abordagem qualitativa, do tipo exploratório e descritivo, fundamentado no método da História Oral de Vida. Este referencial permite a observação da subjetividade advinda das experiências relatadas pelos depoentes, as quaisseregistram como documentos para análise ${ }^{(9)}$. Portanto, a abordagem adequou-se à produção dasnarrativascomas mulheres que vivenciaram histórias de vida com familiares alcoolistas.

As participantes foram sete mulheres, duas filhas, quatro esposas e uma ex-esposa, sendo três destas (uma ex-esposa e duas filhas) referenciadas por umCentro de Atenção Psicossocial Álcool e Drogas (CAPS AD) de um munícipio do interior da Bahia, Brasil e quatro mulheres (esposas) por uma equipe da Estratégia de Saúde da Família (ESF) do mesmo município. Todos os esposos/ ex-esposo/pais das participantes estavam sendo acompanhando por essas instituições no período da pesquisa. A escolha dessas mulheres se deu de forma aleatória, considerando os seguintes critérios de inclusão: mulheres, maiores de dezoito anos, que mantém/mantiveram relações de convivência com esposos/ex-esposo/pais alcoolistas por período superior a um ano e em condições para a expressão da linguagem oral. Outro critério foi o álcool ser a única substância psicoativa consumida pelos esposos/ex-esposo/pais das participantes.A ex-esposa foi selecionada para participar da pesquisa porque ela mantém os vínculos com o ex-companheiro, estabelecendo ainda o cuidado e prestando apoio.Não foram incluídas na pesquisa as mulheres que não conviviam/conviveram com o esposo/ex-esposo/pai em condição de alcoolismo. 
O espaço social de interlocução para produzir as narrativas das histórias de vida das mulheres participantes do estudo foram os próprios domicílios, após obter sua autorização. As narrativas ocorreram por meio da técnica de entrevista semiestruturada, utilizando como tema disparador: "Fale um pouco sobre sua experiência de convívio com um familiar alcoolista". Cumpriram-se as etapas requeridas pelo método da História Oral de Vida: pré=entrevista, entrevista, pós-entrevista ${ }^{(9)}$.

As entrevistas foram realizadas no período de maio a julho de 2019,registradas em áudio, mediante gravador digital, com o consentimento das mulheres.Cada entrevista teve a duração média de Ihorae 30 minutos e as participantes se encontravam sozinhas no domicílio no momento da entrevista.

Segundo o método da História Oral deVida, após o desenvolvimento das entrevistas segue-se a análise das narrativas, a qual permeia etapas que se inicia pela transcrição. Consiste na passagem do oral para o escrito de forma fiel, até a conferência e autorização resultante da leitura final dos textos, e posterior autorização das participantes do estudo, finalizando com o retorno das histórias orais ${ }^{(9)}$.

Assim, o processo de análise das narrativas, que ocorreu por meio da técnica de Análise de Conteúdo Temática de Bardin ${ }^{(10)}$, desenvolveu-se seguindo os passos: constituição do corpus (transcrição das entrevistas na íntegra e organização do texto), seleção das unidades de contexto (parágrafo), identificação e registro dos temasemergentes;agrupamento em categorias empíricas; interpretação e inferências. Os resultados são apresentados em parágrafos que expressam sínteses interpretativas dos pesquisadores relacionadas às categorias temáticas e fragmentos de narrativas dos participantes, no sentido de corroborar com as interpretações.

Obtiveram-se neste estudo as seguintes categoriastemáticas:Categoria I -Sofrimentospsicossociais das muIheres resultantes das relações desiguais de gênero e da codependência; Categoria2 -Expressões da relação desigual de gênero e o processo de resiliência das mulheres diante da codependência com o familiar alcoolista.

O projeto foi submetido ao Comitê de Ética em Pesquisa com Seres Humanos, sendo aprovado com o parecer $n^{\circ}$ 3.233.649. Apresentou-se a cada participante o Termo de Consentimento Livre e Esclarecido (TCLE) informando-se quanto aos riscos, benefícios e objetivos do estudo, sendo assinado pelas participantes do estudo. Para preservar o anonimato, as participantes filhas foram identificadas por codinomes de pássaros e as esposas/ ex-esposa por codinomes de flores.

\section{RESULTADOS}

Descrição das participantes

As sete mulheres participantes da pesquisa foram: duas filhas,quatro esposas e uma ex-esposa,com idade entre 21 e 78 anos; a maioria com renda mensal inferior a $\mathrm{R} \$ \mathrm{I} .000,00$ (mil reais); religião católica (quatro); Ensino Fundamental completo (quatro); Do lar (quatro); Agente Comunitária (uma), Enfermeira (uma), Estudante de Ensino Superior (uma).Das participantes,quatro mantêm relação conjugal com o companheiro e uma separou-se definitivamente há dois anos. Em relação ao alcoolismo dos esposos/ex-esposo, três permanecem em consumo abusivo do álcool, um está em reabilitação, em abstinência há dois anos, e um em controle de redução de danos assistido no CAPS AD.Em relação às filhas, estasrelataramque a história do alcoolismo do pai remontaa períodos que antecederam ao nascimento delas, persistindo até a vida adulta, sendo que os pais atualmente se encontram em abstinência, um por motivos de saúde e o outro por meio de reabilitação em uma clínica.

Categoria I - Sofrimentos psicossociais das mulheres resultantes das relações desiguais de gênero e da codependência

Nessa categoria foram elencadosfragmentos de narrativas das participantes do estudo, referentes ao sofrimento psicossocial que ocorre na relação desigual de gênero e de codependência com familiares alcoolistas.

Identificou-se que o fenômeno vivido pelas mulheres, filhas, esposas, ex-esposa revelou-se de maneira singular em cada contexto de vida. Entre as características em comum vivenciadas por algumas participantes, destaca-se o enfrentamento do estigma do alcoolismo, pois a sociedade e alguns familiares não reconheciam o alcoolismo como doença. Assim, elas passaram a sofrer sintomas graves da codependência, como a culpa e o bloqueio social, que proporcionaram por sua vez, a fragilidade, a inferioridade, além da restrição e isolamento social.

"[...] Para a gente não tinham aquele olhar mais atencioso, era sempre um olhar à distância. Então, a gente sempre vai deixando marcas e mágoas."(Águia - Filha)

“[...] Então, isso já teve até na família, que, às vezes, quando tinham eventos as próprias irmãs dele não convidavam ele, porque diziam que ele ia acabar com a alegria do povo, ia acabar com a festa.Então para a gente isso foi machucando; é tanto que criou um bloqueio que até hoje a gente tem um pouco de afastamento da família."(Margarida-Cônjuge)

"[...] se der errado eu me sinto culpada, se acontecesse alguma coisa com meu filho eu me sinto culpada, ou com minha filha, ou até com ele se acontecer coisa ruim eu me sinto culpada". (Copo-de- leite-Cônjuge)

Além do sofrimento associado à codependência, as muIheres vivenciam o sofrimento resultante da disfunção familiar. Elas relataram que as demonstrações de afeto e carinho bem como os momentos de lazer deixaram de existir entre 
os familiares, favorecendo o distanciamento entre os membros, como podemos observar nos relatos seguintes:

"Sempre senti falta da figura paterna exemplar dentro de casa. Porque não existe, por exemplo, o abraço. A minha família é muito carente de afeto, eu digo isso porque, de uns três anos para cá, começamos a comemorar o aniversário da irmã e nos reunir. A gente puxou o gênio dele, então, a família teve um saldo negativo nisso, por causa da bebida dele."(Sabiá- Filha)

"Ele nunca foi um pai de se programar para a gente ter um lazer, fazer uma viagem..., e quando tinha oportunidade, ele desfazia, então, à gente odiava, a gente nunca sabia o que era uma viagem, ir a uma praia." (Águia - Filha)

"[...] O álcool causa desunião em casa, brigas, discussões." (Dália-Cônjuge)

"[...] Ele preferiu mais a bebida, as pessoas lá fora do que a família, ele destruiu a família[...].'(Copo-de-leite - Esposa)

O convívio com o homem alcoolista é relatado ainda associado à limitação do viver das mulheres, já que estas se veem como responsáveis/cuidadoras dos esposos/pais e convivem com as recaídas e sobrecarga do cuidado.Assim, são impossibilitadas de estabelecerem uma rotina de autocuidado e atividades sociais com a família, resultando em um processo de adoecimento, como apresentados nos relatos a seguir:

"[...] Não é fácil a vida hoje minha é limitada mesmo. Quando eu me sobrecarrego muito eu fico tensa."(Margarida-Cônjuge)

"[...] Mandei ele, ou deixa a bebida ou eu vou.Aí ele parou uns tempo, pouca hora voltou de novo[...]." (Rosa-Cônjuge)

"A bebida fez mal pra ele. Está matando ele, mas acabou também comigo". (Rosa-Cônjuge)

"Eu era ativa na igreja, não perdia uma missa, não perdia nada, num to mais. Eu to mais isolada, não tenho mais animo pra sair pra lugar."(Copo-de-leite-Cônjuge)

"[...] Antes pra sair assim eu tinha aquela alegria. Hoje em dia eu não ligo pra sair.”(Dália-Cônjuge)

"[...] Chegou um dia que mainha precisou me dar um pedaço de diazepam para eu dormir, porque suco de maracujá e outras coisas assim, calmantes naturais, não fazia efeito em $\operatorname{mim}[$ [...].'(Sabiá- Filha)

A necessidade de controlar e cuidar do outro, sujeitando-se a viver em função do familiar alcoolista, características da codependência, foram relatadas de forma intensa pelas mulheres. Essa relação produz sofrimento psicossocial que se evidenciana expressão de preocupação excessiva, constante sensação de medo, raiva e vergonha, como podem ser vistos nas falas seguintes:

"Eu comecei assim a cobrar a presença dele. Criei uma dependência de estar com ele. Eu tinha que estar com ele sempre e eu tinha dificuldade de estar só."(Margarida-Cônjuge)

"Quando ele interna é eu que acompanho. Aí eu já não consigo dormir, não consigo fazeras coisas direito, já fico agoniada. Eu quero ficar lá [...]."(Águia-Filha)

"Tinha noite que eu nem dormia direito, com medo dele dar alguma coisa."(Rosa - Cônjuge)

"[...] Eu sou um pouco medrosa.Tenho medo de ficar só." (Bem-me-quer -Cônjuge)

"Eu chorava separado para ele não ver que eu estava passando aquela raiva [...]."(Copo-de-leite -Cônjuge)

"[...] Às vezes é constrangedor, é vergonhoso, porque a pessoa fica sem noção, fazendo brincadeiras, piadas sem graças. As pessoas comentam muito [...]."(Águia-Filha)

Percebeu-se nos relatos das participantes da pesquisa que as relações familiares de codependência, aliada às relações desiguais de gênero, são também marcadas por situações de violência sofridas pelas mulheres. Tais episódios são relatados de forma comum e rotineira, sendo elas, cônjuges e filhas, os principais alvos destes atos. As falas demonstram a expressão de diversos tipos de violência através de insultos e até mesmo agressões físicas, causando constante aflição nestas mulheres, que passam a temer a repetição dessas violências.

"[...] Às vezes, assim chegou umas duas ou três vezes meu pai puxar a toalha da mesa e com aquelas travessas de vidro jogar tudo no chão, e a gente ficar sem comer."(Águia- Filha)

“[...] Ele tentou me matar sufocada com o lençol.”(SabiáFilha)

"Eu só vivia momentos de violência fisica e verbal, era violento com a gente [...]."(Sabiá - Filha)

"Eu tenho um sinal aqui, foi a unha dele[...]."(Rosa-Cônjuge)

"[...] Só nunca assim bateu sabe. Mas de ficar naquela agressão chutando alguma coisa com aquele nervoso[...]."(Dália- Cônjuge)

"[...] Me humilhava demais com palavras, com pancadas."(Copo-de-leite-Cônjuge)

"[...] Mesmo ele não estando aqui, mas a pressão psicológica continua a mesma me tranco aqui e fico parada, sentada no sofá, parada."(Copo-de-leite-Cônjuge)

Categoria 2 -Expressões da relação desigual de gênero e o processo de resiliência das mulheres diante da codependência com o familiar alcoolista

Nesta categoria os relatos das mulheres explicitam uma adaptação ao convívio com o familiar alcoolista além de descrever as expressões das relações desiguais de gênero no contexto de codependência, colocando em evidência que, quando o alcoolista é do gênero masculino, as mulheres enfrentam, além das consequências da dependência do familiar, as desigualdades nas relações de gênero, que as colocam em um lugar de submissão.

Neste sentido, identificou-se que o relacionamento construído entre esposas, ex-esposa e filhas e o familiar alcoolista é estruturado de maneira diferente com o 
passar do tempo. As mulheres cônjuges relatam o conformismo e a concordância com a realidade vivenciada:

"Eu não queria que meus filhos sofressem na mão de outro. E não queria também dar o braço a torcer, dizer largou porque não prestava."'(Rosa-Cônjuge)

"Eu já pensei assim umas duas vezes assim de sair, mas eu também olho os meninos(filhos)."(Dália- Cônjuge)

"[...] Nem o álcool foi barreira para eu me casar com ele. Mas eu não chegava em conflito com ele sabe."(MargaridaCônjuge)

"[...] Minha vontade era sumir. Eu ia pra onde? Com minhas criançaspequenas[...]."(Copo-de-leite - Cônjuge)

Já as mulheres filhas entrevistadas, relatam divergência sobre o desejo de continuidade da relação afetiva dos pais:

"[...] Eu chorava e pedia a minha mãe para tirar ele de casa, e minha mãe criada do jeito que foi naquela questão de matrimônio, que tem que ser para vida inteira."(Sabiá - Filha)

"[...] A gente (filhos) não queria que meu pai se separasse da minha mãe[...].”(Águia- Filha)

Percebe-se ainda nas narrativas das mulheres que elas buscam amenizar as atitudes desagradáveis dos homens quando estão alcoolizados, considerando seus atributos e atitudes positivas quando estão sem o efeito do consumo do álcool, aspecto que pode reforçara manutenção das ações abusivas do homem. Assim, a família torna complacentes os maus tratos e malefícios praticados pelo alcoolista, colaborando, desta forma, para perpetuar a codependência e a dependência existente no contexto familiar.

"[...] Fala uma coisinha para o povo, assim [...] de machucar a pessoa mesmo [...]!Aí eu deixo quieto. Aí eu falo com a pessoa e ela fica de boa."(Dália-Cônjuge)

"[...] Passava por cima, porque ele sempre foi muito carinhoso comigo. Então, tinha essas coisas que me equilibrava esse lado ruim dele."(Margarida-Cônjuge)

"[...] Por mais que ele tivesse essas coisas, mas ele tinha um lado bom, era pai da gente, a gente amava e até hoje a gente tem um maior amor por ele."(Águia-Filha)

Diante da manutenção das situações vivenciadas, percebe-se que as participantes desenvolveram atitudes de adaptação, proteção, desejando relações interpessoais amigáveis com o familiar alcoolista. Desta forma, com intuído de amenizar os conflitos familiares, estas mulheres tornam-se passivas diante do pai/esposo, deixando de impor seus desejos para facilitar a convivência familiar, como pode ser observado nas falas seguintes:

"[...] Ai eu até falei com os meninos (filhos), chamei os meninos (filhos), e falei a partir de hoje nós não vai dizer mais nada pra ele vai deixar. Se ele tiver bebendo, ou que não tá, deixa ele fazer o que ele quiser."(Dália- Cônjuge)

"[...] Tem que ter muita paciência. Não é tudo que aquela pessoa conversa que a gente fica repetindo, saia, fica quieta, chega no canto e fica quieta. Pede a Deus orientação que Deus acalma tudo[...]."(Bem-me-quer-Cônjuge)
"Eu ficava em casa, eu não saía, eu tinha medo, muito medo, minha mãe não ficava sozinha nunca, quando eu viajava para algum lugar as minhas irmãs automaticamente já apareciam para ficar com minha mãe." (Sabiá- Filha)

\section{DISCUSSÃO}

A codependência familiar é considerada um transtorno de ordem psíquica, que afeta $o$ aspecto emocional do indivíduo, no qual pessoas que convivem com um usuário de álcool e outras drogas estão suscetíveis a desenvolver um conjunto de sintomas psicopatológicos que se traduzem em um intenso sofrimento psíquico, com graves impactos emocionais e sociais ${ }^{(6-1)}$.

A relação de codependência ocorre quando a convivência com o familiar alcoolista desencadeia uma estruturação disfuncional no desenvolvimento emocional, psicológico, comportamental e espiritual da família. Tal fato gera uma condição de adoecimento conjunto que associado a outras experiências vividas, podem vir a desenvolver a codependência tanto em cônjuges quanto em filhos (as), tornando-os incapazes de viver suas próprias vidas, para viver em função do alcoolista. Portanto, tratase de uma doença, pois o codependente também luta contra o alcoolismo, de maneira crônica e gradativa ${ }^{(7-12)}$.

Famílias que convivem com um membro alcoolista, em especial mulheres, cônjuges e/ou filhas, têm sua rotina modificada.A elas são atribuídas, além das tarefas domésticas, as atividades de cuidado do familiar em situação de dependência, o que resulta em um estado de estresse constante e sobrecarga física e mental ${ }^{(13)}$.

A sobrecarga da convivência e a responsabilidade de cuidar do familiar alcoolista, somada às situações de discriminação e de desigualdade de gênero no âmbito familiar e social contribuem para o comprometimento da saúde física e emocional das mulheres codependentes. Tendo em vista essa realidade, o cuidado psicossocial para a família na perspectiva de gênero, com enfoque na mulher em adoecimento crônico deve ser considerado prioridade para que se alcance a integralidade da atenção à saúde.

Neste sentido, afirma-se que a mulher ao se tornar cuidadora de um familiar alcoolista vivencia desafios no seu cotidiano, incluindo a perda da qualidade de vida e a diminuição do autocuidado. Desse modo, no cenário da codependência com o alcoolismo, a mulher cuidadora se apresenta com suas capacidades funcionais comprometidas $^{(7-13)}$.Observou-se nesta pesquisa que as mulheres viviam na condição de codependentes e não estavam exercendo o autocuidado, ainda com a anulaçãodas atitudes e desejos pela vontade do pai/cônjuge/ex-cônjuge, além de demonstrarem dificuldade na manutenção das atividades cotidianas e na interação social com a família e a comunidade. Destaca-se também que as esposas, ex-esposa e as 
filhas que participaram desse estudo apresentavam sinais de exaustão emocional, culpa excessiva, tristeza, medo e angústia diante da situação em que se encontravam.

Dentre as principais manifestações biopsicossociais decorrentes dessa relação de codependência familiar é possível observar a presença de sentimentos como raiva, tristeza, angústia, vergonha, culpa, baixa autoestima e sentimento de vazio ${ }^{(7-12)}$. Tais sentimentos levam a condutas que intensificam ainda mais o sofrimento e adoecimento, a exemplo do isolamento social, autoanulação, dificuldades laborais e até mesmo suicídio(14-15).

Sobre esses aspectos, constatou-se nesse estudo que oconsumo abusivo do álcool pelo pai/esposo/ex -esposo das participantes acarretou a fragilização dos vínculos familiares, destacando-se neste sentido, a falta de demonstração de afeto, distanciamento e a indisponibilidade do pai/esposo em estabelecer relações saudáveis com as filhas/esposas.

Diante dessa perspectiva, percebe-se que as mulheres que participaram do presente estudo, vivenciaram uma situação de sofrimento emocional e assim como seus familiares alcoolistas, elas também estão em um estado de adoecimento crônico em decorrência dessa condição de codependência e da função de cuidadoras ${ }^{(12,13,16)}$. Afirmase deste modo que as repercussões do alcoolismo interferem na dinâmica familiar e nos aspectos da saúde física e psíquica dos cuidadores.

As repercussões psíquicas sofridas pelos codependentes fazem com que os mesmos apresentem diversos comportamentos impulsivos que influenciam sua rotina e de sua família. Estas atitudes geraram conflitos internos nas mulheres apresentadas neste estudo, principalmente a impotência. Destaca-se que o intenso cuidado do familiar ao alcoolista e a não obtenção de resultados no processo terapêutico proporciona a perda da esperança ${ }^{(I I)}$.

Diante do exposto, os vínculos familiares enfraquecidos podem ter suas causas no cenário conflituoso propiciado pela convivência com a problemática do alcoolismo, como por exemplo, os comportamentos agressivos frequentes, dificuldade no acolhimento do alcoolista e outros membros; e a inexistência de diálogos, o que provoca o distanciamento das pessoas, com consequente isolamento social ${ }^{(7-11,14-16)}$.

Entre as situações que promovem o sofrimento psíquico das mulheres está a violência doméstica, que por sua vez tem como potencializador o álcool consumido pelos cônjuges e pais ${ }^{(17)}$, sendo que a violência é um reflexo da realidade conservada desde a antiguidade ${ }^{(8)}$. A desigualdade de gênero instalada na sociedade desde a antiguidade distorce os papeis desenvolvidos pela mulher e pelo homem em seus meios de convivência, o que proporciona o poder de comando a ele, que por sua vez exerce sua autoridade sobre as mulheres a sua volta $^{(18)}$. Complementando essa reflexão, tem-se que a violência contra a mulher está presente em qualquer atitude violenta, tanto emocional, física e/ou sexual, ligada ao seu gênero, tendo seus parceiros como principais algozes de tais $\operatorname{atos}^{(4)}$.

Nesse contexto, salienta-se que o homem traz consigo o patriarcalismo como concepção para impor superioridade sobre a mulher, tendo por ela um sentimento de propriedade, que objetiva sua dominação, desenvolvendo uma falsa concepção por parte dele de legitimidade em agir de forma agressiva para coerção, quando o mesmo identifica a fragilidade da esposa ou filha ${ }^{(5)}$.

As mulheres vítimas desse tipo de violência, em sua maioria, vivem em situação de desigualdade de gênero, fragilidade emocional e falta de apoio. Por esses motivos acabam ficando sem opções para defesa, permitindo inconscientemente $o$ avanço do poder masculino e a crescente rotina de atos violentos e hostis ${ }^{(3-8)}$.

Ao relatar os diferentes tipos de violências sofridas pelos seus companheiros, as mulheres desta pesquisa trouxeram traumas psicológicos que as limitaram de realizar atividades simples do dia-a-dia. As filhas por sua vez, queixaram-se da agressividade, violência verbal e psicológica dos pais contra elas. Afirma-se assim, que o enfrentamento do alcoolismo do pai/esposo gerou nas participantes da pesquisa adoecimento a nível biopsicossocial. Neste sentido, a codependência vivenciada por elas, acrescido ao alcoolismo, proporciona ao homem um espaço a mais para exercer sua masculinidade de forma agressiva e opressiva sobre elas, desde a demonstração dos sentimentos, até ao isolamento social.

A partir dessas discussões, evidenciam-se as repercussões psicossociais atreladas à relação de codependência estabelecida por cônjuges e filhas diante da condição patológica de seus esposos/ex-esposo e pais, respectivamente. A vulnerabilidade no contexto familiar de convivência com o alcoolismo ratifica a necessidade de inserção da família na rede de atenção psicossocial ou de saúde, para que ela, juntamente com o membro alcoolista, seja foco do cuidado e receba todo suporte necessário para sua reabilitação.

A complexidade que envolve a codependência não determina a forma como cada pessoa manifestará os efeitos dessa experiência.Assim, algumas pessoas se apresentam debilitadas e adoecidas em decorrência dessa vivência, enquanto outras são afetadas de maneira moderada ${ }^{(2-6)}$.

Observa-se que algumas famílias podem assumir uma postura de protecionismo ao familiar alcoolista no sentido de intervir por ele na tomada de decisões quanto ao consumo do álcool, impedindo que consequências advindas de suas atitudes o atinjam, assumindo para si as responsabilidades de atos que não foram seus. Essa forma de manejo interfere significativamente no 
processo de abstinência do usuário, pois esses comportamentos permissivos podem reforçar a manutenção do uso de drogas ${ }^{(7-16)}$.

Com o passar do tempo, as mulheres podem começar a aceitar suas realidades como algo comum e não encarar o alcoolismo como doença. Mesmo tendo conhecimento das ações negativas executadas por esposos e pais, as mulheres desta pesquisa demonstraram compaixão e piedade pelo familiar alcoolista, pois o vínculo existente entre eles já foi estabelecido concomitante ao consumo do álcool ${ }^{(16)}$.

A convivência com o familiar alcoolista ainda propiciou às participantes deste estudoo desenvolvimento de sentimentos exacerbados de apego, influenciando no modo de enfrentar a realidade e dificultando o rompimento da relação opressora do pai/cônjuge. Identificou-se nos relatos das esposas que o medo da solidão, de ficarem sozinhas e desamparadas propiciou uma distorção da realidade vivenciada, a ponto de elas acreditarem que estavam na posição de superiores na relação com o familiar alcoolista.

Essa ambiguidade nas ações é inerente à forma como as pessoas percebem o mundo e suas relações com o outro. Ao adotarem tal conduta, evidencia-se que essas mulheres camuflam seus sentimentos diante do sofrimento vivenciado com elementos que as mantenham confortáveis e que de alguma maneira as completem. Muitas esposas e filhas assumem essa postura por questões éticas, a fim de serem aceitas pela sociedade e não receberem julgamentos morais ${ }^{(19)}$.

Essa conduta ambígua foi evidenciada nas mulheres que constituíram esse estudo, pois mesmo diante dos comportamentos inadequados do familiar alcoolista, as mesmas se mostravam compreensivas e resilientes sob a justificativa de que eles eram seus companheiros ou pais, colocados em suas vidas por Deus e por isso não poderiam abandoná-los. Sabe-se que o vínculo é essencial para o desenvolvimento saudável da relação entre os membros que compõe uma família. Contudo, relações familiares marcadas pelo alcoolismo podem ser caracterizadas pela descontinuidade dos vínculos afetivos, pois há dificuldade em estabelecer regras, limites e a união entre os indivíduos ${ }^{(15-16)}$.

Sobre essas premissas, constata-se que existe uma persistência no ir e vir dessas famílias entre o desejo de mudar e continuar no comodismo. Neste sentido, a situação vivenciada pela codependência além do desgaste emocional da relação familiar favoreceu que as mulheres da pesquisa não assumissem uma postura necessária para uma mudança ou de autovalorização(20).
Somados a essa questão, existem os aspectos socioculturais que podem determinar a perpetuação desse tipo de relação afetiva. Tais aspectos se associam ao contexto em que se insere o cotidiano dessas mulheres e por isso, englobam as interações interpessoais estabelecidas nos ambientes domésticos e externos a ele, e também valores e proposições culturais arraigados socialmente, impondo condutas específicas para a mulher ${ }^{(3-5)}$.

\section{CONCLUSÃO}

A convivência com o familiar alcoolista repercute de diversas formas na vida da família, refletindo negativamente nas relações familiares, bem como na construção de vínculos afetivos. Este estudo possibilitou a constatação de que essa convivência resulta em uma condição de codependência, com severo adoecimento físico e psíquico para os membros familiares envolvidos.

Ademais, a codependência, para mulheres, cônjuges e/ou filhas, contribui para o estabelecimento de um estado de apatia e conformismo diante da problemática do alcoolismo. Essa premissa colabora para a perpetuação de eventos estressores e violentos que são comuns em relações em que exista um familiar alcoolista e, consequentemente, da exacerbação de sinais e sintomas biopsicossociais.

Observou-se que há diversas pesquisas sobre a codependência, mas existe uma lacuna de material que relacionem esta temática com a perspectiva de gênero, o que revela a importância de estudos que enfatizem a figura da mulher, seu papel enquanto cuidadora e das consequências relativas a este cuidado, a exemplo do sofrimento emocional e diversos modos de adoecimento.

Em suma, o consumo abusivo do álcool por algum familiar fragiliza as relações entre os membros da família e intensifica o sofrimento, seja físico ou mental do cuidado e também do alcoolista. Devido a sua magnitude, é imperativo aprofundar o conhecimento sobre as características da mulher em situação de codependência, para eliminar condições de desigualdade e favorecer a construção de um cuidado direcionado e individualizado.

Deste modo, as equipes de saúde devem incluir os familiares no Projeto Terapêutico Singular (PTS) do usuário, visando fortalecer os vínculos entre eles, ofertar a assistência aos cuidadores, contribuindo para a promoção da saúde mental. A inclusão da família no plano de cuidados do alcoolista se constitui como estratégia fundamental para alcance do êxito nas ações de saúde sob uma ótica holística e integral. 


\section{REFERÊNCIAS}

I. Santos CEM, Medeiros FA, Buzo JAM, Barbosa MFA, Santos BA. Representações de alcoolistas sobre a história de envolvimento com o álcool. Arch Health Invest [Internet]. 2017 [acesso em I5 mai 2020]; 6(I): 37-42. Disponível em:http://dx.doi.org/I0.2I270/archi.v6il.I 775

2. Silva MP, Oliveira AMN, Silva PA, Algeri S, Flores MCS. Codependência química: percepção de familiares de usuários de substâncias psicoativas de uma comunidade terapêutica do Sul do Brasil. Rev. Enferm. Atual In Derme [Internet]. 2018 [acesso em 17 mai 2020]; 86(24). Disponível em: https://revistaenfermagematual.com.br/index.php/revista/article/view/562

3. Tucci BFM, Oliveira MLF. Repercussões do uso abusivo de bebida alcoólica nas relações familiares de trabalhadores da construção civil.Ciênc. cuid. saúde. [Internet]. 2019 [acesso em 17 mai2020]; 18(2) e42903. Disponível em: http://periodicos.uem.br/ojs/index. php/CiencCuidSaude/article/view/42903/pdf

4. Carpanez TG, Lourenço LM, Bhona FMC. Violência entre parceiros íntimos e uso de álcool: estudo qualitativo com mulheres da cidade de Juiz de Fora-MG. Pesqui. prát.Psicossociais[Internet]. 2019 [acesso em 17 mai 2020]; 14(2): I- I8. Disponível em: http:// pepsic.bvsalud.org/scielo.php?script=sci_arttext\&pi$d=S|809-890820| 90002000|2 \&| n g=p t \& n r m=$ iso

5. Moraes MSB, Cavalcante LIC, Pantoja ZC, Costa LPViolência por parceiro íntimo: características dos envolvidos e da agressão. PsiUnisc. [Internet]. 2018 [acesso em 17 mai 2020];2(2):78-96. Disponível em: https://online. unisc.br/seer/index.php/psi/article/view/ I 190 I/74I I

6. Diehl A, Silva D, Bosso AT. Codependência entre famílias de usuários de álcool e outras drogas: de fato uma doença? Revista Debates em Psiquiatria[Internet]. 2017 [acesso I 7 mai 2020];7(I):34-42. Disponível em: https:// abpbrasil.websiteseguro.com/rdp I 7/0I/rdp0I.pdf

7. Melo CF, Cavalcante IS. A Codependencia em Familiares de Adictos. Rev. Pesqui. [Internet]. 2019 [acesso em 25 mai 2020]; I (n. esp):304-3 I0. Disponível em: http:// dx.doi.org/I0.9789/2I75-536I.20I9.v I Ii2.304-3 I0.

8. Carvalho MRS, Oliveira JF, Gomes NP, Santos MM, Estrela FM, Duarte HMS. Interface entre a violência conjugal e o consumo de álcool pelo companheiro. Rev. bras. enferm [Internet]. 2018 [acesso em 17 mai 2020];7 I (Suppl5 ): 2109-2I I 5. Disponível em:http://dx.doi.org// 0.1590/0034-7/67-2017-0540

9. Meihy JCSB, Holanda F. História Oral: como fazer, como pensar. $2^{\mathrm{a}}$ ed, São Paulo: Contexto, 2013.

10. Bardin L. Análise de conteúdo. $6^{\mathrm{a}}$ ed. Lisboa: Edições 70; 2011 .

II. Oliveira EB, Santos MB, Guerra OA. O trabalho como estratégia de reinserção psicossocial do dependente químico sob a ótica da família.Rev. port. enferm. saúde men-
tal[Internet]. 2019 [acesso em 18 mai 2020]; (21):23-30. Disponivel em: http://dx.doi.org//0.19131/rpesm.0234

12. Bortolon CB, Signor L, Moreira TC, Figueiró LR, Benchaya MC, Machado $C A$,et al. Family functioning and health issues associated with codependency in families of drug users. CienSaudeColet[Internet]. 2016 [acesso 25 mai 2020];2I(I):101-107. Disponívelem: I0.1590/|4|3-8|2320|52||.206620|4

13. Maciel SC, Silva FF, Pereira CA, Dias CCV, Alexandre TMO. Cuidadoras de dependentes químicos: um estudo sobre a sobrecarga familiar. Psic.: Teor. e Pesq[Internet]. 2018 [acesso em 25 mai 2020]; 34(e344I6). Disponível em: https://dx.doi.org/I0.1590/0I02.3772e344I6

14. Fernandes AM, Soares AB. Codependentes de substâncias psicoativas: percepção de suporte social e qualidade de vida. Contextos Clín[Internet]. 2018 [acesso em 17 mai 2020];। I(2):206-216. Disponível em: http://pepsic.bvsalud.org/scielo.php?script=sci_ arttext\&pid=S1983-34822018000200007

I5. Rodrigues G, Krindges CA. Consequências psicossociais atreladas ao consumo precoce de bebida alcoólica.Rev. psicol. IMED[Internet]. 2017 [acesso em 22 mai 2020]; 9(2): 6I-76. Disponível em: https://doi. org/I 0.18256/2 I 75-5027.2017.v9i2.2087.

16. Cyrino LAR, Araujo BB, Santos CC, Baptista LV.A codependência familiar de indivíduos que fazem o uso abusivo de álcool. Revista Cesumar [Internet]. 2016 [acesso em 17 mai 2020]; 2 I (2): 457-470. Disponívelem:https://periodicos.unicesumar.edu.br/index.php/ revcesumar/article/view/3563

17. Nadda A, Malik JS, Bhardwaj AA, Khan ZA, Arora V, Gupta S, et al. Reciprocate and nonreciprocate spousal violence: A cross-sectional study in Haryana, India. J Family MedPrimCare [Internet]. 2019 [acesso em28 mai 2020]; 8(I):I20-4. Disponível em: http://www. jfmpc.com/text.asp?20 I9/8/I/I20/25 I I56

18. Saffioti HIB. Gênero, patriarcado,violência. I ${ }^{a}$ ed. São Paulo: Editora Fundação Perseu Abramo, 20II.

19. Sena ELS, Boery RNSO, Carvalho PAL, Reis HFT, Marques AMNAIcoolismo no contex to familiar:um olhar fenomenológico.Texto \& contexto enferm[Internet].201 I [acesso em 18 mai 2020];20(2):310-8.Disponível em:https://www.scielo.br/scielo.php?pid=S0 I04=070720 I I0002000 |3-\&scriptsci_abstract\&tlng=pt

20. Muniz KRA, Xavier AR, Santana JR. O uso abusivo de álcool e as heranças transgeracionais no âmbito familiar. InterdisciplinaryScientificjournal[Internet]. 2019 [acesso em 17 mai 2020]; 6(3): I40-I58. Disponível em: http://dx.doi.org/ | 0.17| I5/2358-84 I I/v6n3a08

Recebido: 2020-10-05

Aceito: $2020-1 \mid-27$ 